\title{
PECULIARITIES OF HEATING OF STAMPED BILLETS IN NON-CONSUMABLE ELECTRODE ELECTROSLAG SURFACING
}

\author{
O.G. KUZMENKO \\ E.O. Paton Electric Welding Institute, NASU \\ 11 Bozhenko Str., 03680, Kiev, Ukraine. E-mail: office@paton.kiev.ua
}

\begin{abstract}
Peculiarities of heating of stamped billets in non-consumable electrode electroslag surfacing were investigated experimentally and by methods of mathematical modelling. It is determined that fast electroslag heating of billet for further surfacing with relatively low consumption of electric energy and heat saturation of base metal is achieved by specific power maintained at $(150-180) \cdot 10^{4} \mathrm{~W} / \mathrm{m}^{2}$ level. At that, it is necessary to maintain surfacing voltage and depth of slag pool at the possible minimum level. 11 Ref., 8 Figures.
\end{abstract}

$\boldsymbol{K} \boldsymbol{e} \boldsymbol{y} \boldsymbol{w} \boldsymbol{o} \boldsymbol{r} \boldsymbol{s}: \quad$ electroslag surfacing, non-consumable electrodes, specific power, stamps, thermophysical processes

Producing the quality joint of layers in electroslag surfacing (ESS) by liquid metal and noncompact materials requires heating of surface of stamp being deposited up to submelting. At that, uniform submelting of stamp being deposited through the height and area of worn working surface is necessary to be provided.

The practice of electroslag technology application shows that intensity of heat effect of slag pool on base metal depends on current and voltage values as well as slag pool depth [1-7]. If electroslag process is carried out with the help of one non-consumable graphitized electrode at constant power, then reduction of voltage and slag pool depth is accompanied by rise of slag temperature under the electrode and its decrease aside of the electrode at more than $30-60 \mathrm{~mm}$ distance [2, 4]. Works [2, 4] did not consider the effect of these parameters on heating efficiency of the whole surface of billet.

It was necessary to investigate the effect of ESS mode parameters on the next characteristics of electroslag process:

- duration of base metal heating up to its surface burning-off;

- distribution of temperature through the height of heated billet;

- consumption of electric energy and possibilities of rise of its application efficiency.

Several series of experiments were carried out for investigation of main dependencies of electroslag heating of solid metal using non-consumable electrode. The experiments were carried out using AN-15M flux on full-scale specimens from $5 \mathrm{KhNM}$ steel applying temperature measurements by thermocouples installed at different levels through the height of billet being heated, and control of metal state near surface by steel rod. The investigations on full-scale specimens had

(C) O.G. KUZMENKO, 2015 wide combination with calculation of heating parameters by mathematical model described in works $[8,9]$. Figure 1 gives the calculation results on heating of stamp billet of $H=400 \mathrm{~mm}$ height at $q=125 \cdot 10^{4} \mathrm{~W} / \mathrm{m}^{2}$ specific power of heat input in slag pool.

Relatively constant temperature of slag pool $T_{\mathrm{s}}$ is quickly set from the very beginning of the process and formation of skull on the surface of cold metal. Increase of temperature of metal surface $T_{\mathrm{m}}$ provides for reduction of skull thickness $\delta_{\mathrm{sk}}$ and rise of heat transfer coefficient $k_{\mathrm{s}-\mathrm{m}}$, i.e. efficiency of electroslag heating grows. Value of specific heat flow from slag pool in metal $q_{\mathrm{s}-\mathrm{m}}$ at that does not have significant changes - (21.526.9) $10^{4} \mathrm{~W} / \mathrm{m}^{2}$. Coefficient of heat transfer rapidly increases directly up to complete skull melting. Also, rapid rise of heat flow in metal is observed and billet heating is accelerated. Quasiequilibrium between the temperatures of slag pool and metal is set after skull melting, that provokes for their gradual growth and reduction of specific heat flow $q_{\mathrm{s}-\mathrm{m}}$ from $50 \cdot 10^{4}$ to $25.8 \cdot 10^{4} \mathrm{~W} / \mathrm{m}^{2}$.

Experiments determined that rise of ESS specific power reduces time of base metal heating up to submelting of its surface and increases gradient of temperature through its height ( $\mathrm{Fi}^{-}$ gures 2 and 3 ).

The most significant effect of specific power on these characteristics is observed at its relatively low values. This effect is insignificant in the range of high $q$ values (see Figures 2 and 3 ). The reason of this effect lies in stabilizing the temperature of slag pool due to increase of evaporation of slag volatile components and high heat emission from the surface of slag pool. Effect of specific power on heating duration becomes more apparent in melting of billets of larger height. The high value of specific power $\left(150 \cdot 10^{4} \mathrm{~W} / \mathrm{m}^{2}\right.$ and more) allows heating billets of different height up to submetling approximately during the same time (see Figure 2). 


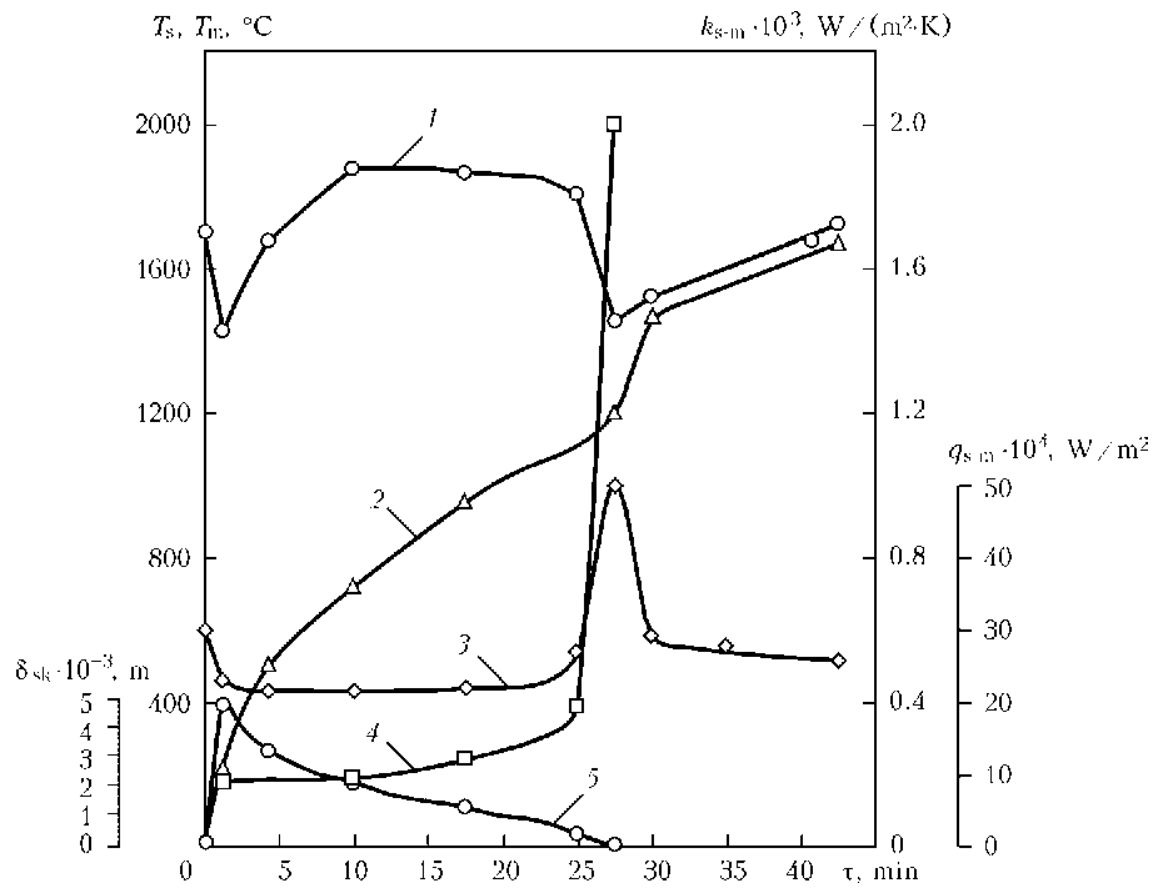

Figure 1. Dependence of temperature of slag pool $T_{\mathrm{S}}(1)$ and surface of billet being surfaced $T_{\mathrm{m}}(2)$, specific heat flow $q_{\mathrm{s}-\mathrm{m}}(3)$, coefficient of heat transfer $k_{\mathrm{S}-\mathrm{m}}$ to metal (4), and skull thicknesses $\delta_{\mathrm{sk}}$ on ESS duration $\tau$ (5)

Figure 4 shows distribution of temperatures through the height of $400 \mathrm{~mm}$ thickness billet depending on duration of its surface heating up to submelting $\left(1510{ }^{\circ} \mathrm{C}\right.$ on the surface).

Quick heating of the surface promotes for reduction of depth and temperature of metal heating-through. The billet is heated up to $200{ }^{\circ} \mathrm{C}$ at $200 \mathrm{~mm}$ depth during $1 \mathrm{~h}$. The experiments also determined that duration of heating of stamped billets of more than $300 \mathrm{~mm}$ height using specific power of ESS of $140 \cdot 10^{4} \mathrm{~W} / \mathrm{m}^{2}$ and more has low dependence on its height (Figure 5).

Application of large specific power of ESS results in intensive heating-through of only upper part of the billet and heat has no time to spread in body of metal being heated. This simplifies the task of heating of the large height stamps.

Effect of voltage on efficiency of electroslag process was evaluated in experimental way. Stamp billet was heated with low specific power $(60-65) \cdot 10^{4} \mathrm{~W} / \mathrm{m}^{2}$ up to setting on the surface of equilibrium temperature, above which the metal is not heated. After that the voltage was

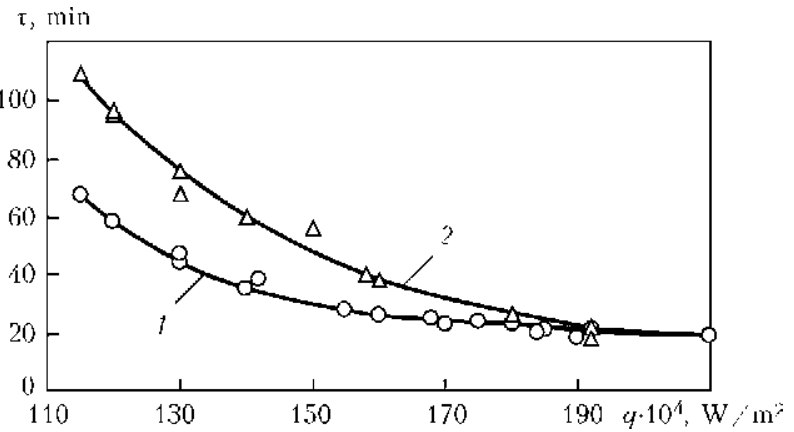

Figure 2. Effect of specific power of ESS on duration of heating of stamped billets up to submelting: $1-180 \mathrm{~mm}$ height; $2-400 \mathrm{~mm}$ changed at stable specific power and temperature of metal being heated was registered.

As can be seen from Figure 6, reduction of voltage provides for higher temperatures on the billet surface. i.e. its heating is intensified.

This can be explained by approaching the zones of active heat emission to metal surface

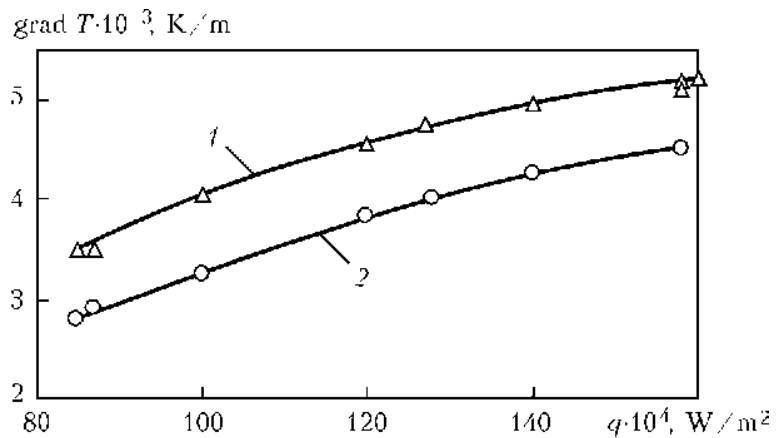

Figure 3. Effect of ESS specific power on temperature gradient through the height $(H=110 \mathrm{~mm})$ of stamped die: 1 - in the upper part of billet; 2 - through the whole billet height

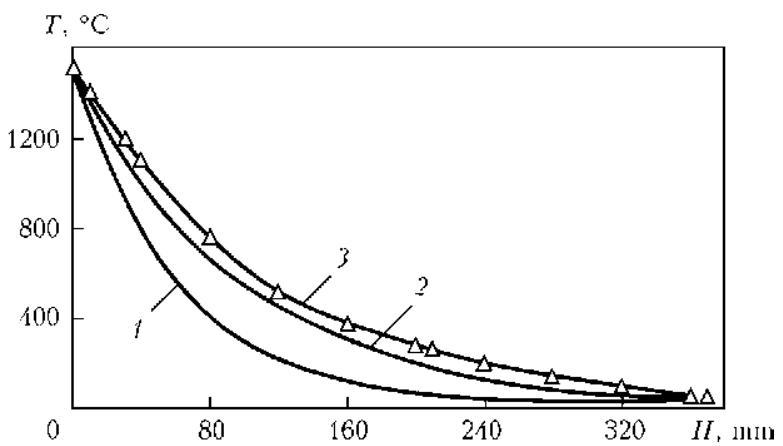

Figure 4. Dependence of temperature distribution through stamped billet height $(H=400 \mathrm{~mm})$ on time of heating: $1-22 ; 2-58 ; 3-68 \mathrm{~min} ; 1,2-$ calculation data; 3 - experimental 


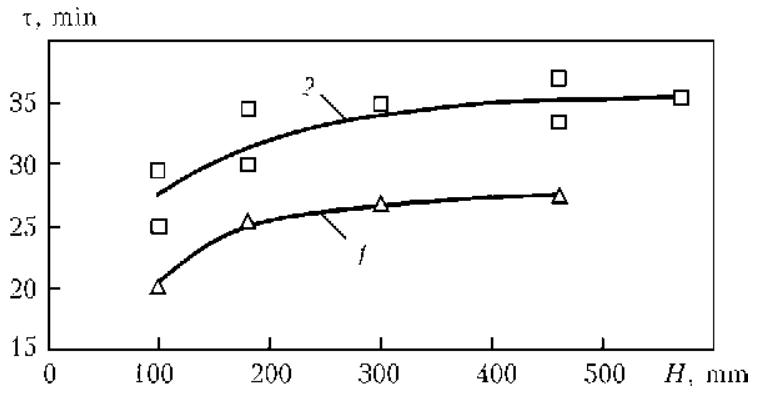

Figure 5. Duration of stamped billet heating of different height: 1 - up to skull melting; 2 - up to metal submelting $\left(q=(140-160) \cdot 10^{4} \mathrm{~W} / \mathrm{m}^{2}\right)$

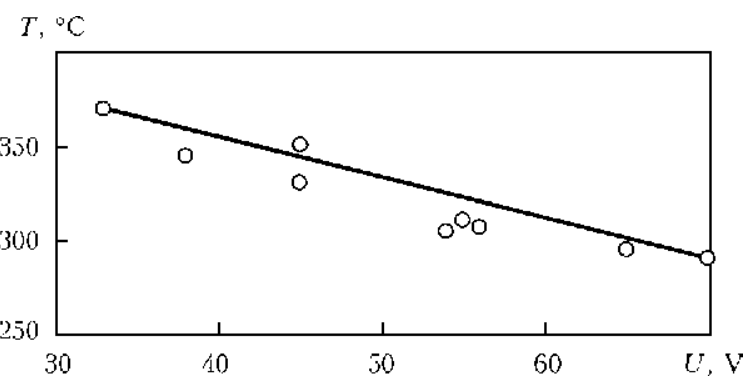

Figure 6. Effect of electroslag process voltage on temperature of stamp surface $\left(H=300 \mathrm{~mm}, q=(60-65) \cdot 10^{4} \mathrm{~W} / \mathrm{m}^{2}\right)$

[8], reduction of heat loss for radiation from slag pool mirror and acceleration of slag pool mixing, that rises the value of heat transfer coefficient $[2,10,11]$

The effect of slag pool depth on intensity of heating of $180 \mathrm{~mm}$ height billet at $150 \cdot 10^{4} \mathrm{~W} / \mathrm{m}^{2}$ specific power was investigated. Moments of skull melting and submelting of billet metal were registered. Received results (Figure 7) indicate reduction of heating duration at decrease of slag pool depth.

Reduction of heating duration in decrease of slag pool depth is explained by approaching the zone of active heat emission to the surface of metal and reduction of heat flow, entering the walls of water-cooled mold. However, its excessive reduction can promote deterioration of stability of electroslag process. Therefore, 50$60 \mathrm{~mm}$ is the optimum depth of slag pool at ESS of stamped billet.

Reduction of heating duration in general results in decrease of electric energy consumption, including at rise of specific power of electroslag process (Figure 8 ).

Energy consumption rises with increase of specific power only in the range of large specific powers, when, as was shown above (see Figure 2), metal heating duration does not depend on this index.

At that, heating of the higher billet in whole requires more electric energy per $1 \mathrm{~m}^{2}$ of the surface. Thus, it was found by investigations that ESS specific power maintained at (150$180) \cdot 10^{4} \mathrm{~W} / \mathrm{m}^{2}$ level provides for fast heating of stamp billet up to surface submelting at relatively small consumption of electric energy and

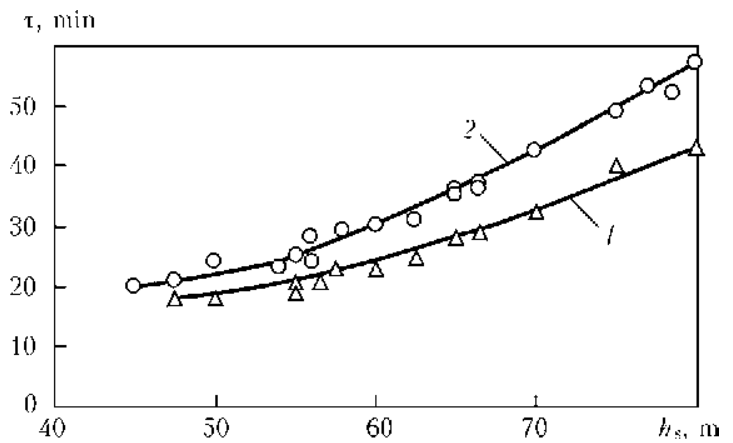

Figure 7. Effect of depth of slag pool $h_{\mathrm{s}}$ on duration of electroslag process: 1 - up to melting of skull; $2-$ up to metal submelting $\left(H=300 \mathrm{~mm}, q=(140-160) \cdot 10^{4} \mathrm{~W} / \mathrm{m}^{2}\right)$

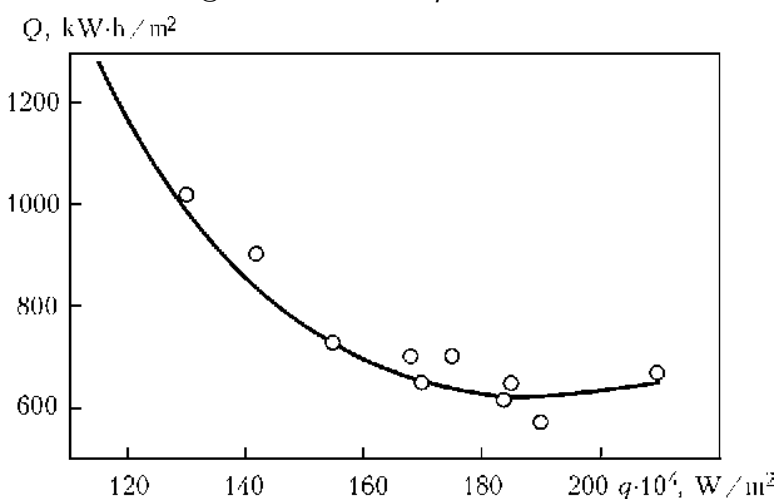

Figure 8. Effect of ESS specific power on electric energy consumption at heating up to submelting of stamps of $180 \mathrm{~mm}$ height

heat saturation of the base metal. At that, voltage and depth of slag pool shall be maintained at the most possible minimum level.

1. (1980) Electroslag welding and surfacing. Ed. by B.E. Paton. Moscow: Mashinostroenie.

2. Lyuty, I.Yu., Latash, Yu.V. (1982) Electroslag melting and refinement of metals. Kiev: Naukova Dumka.

3. Latash, Yu.V., Medovar, B.I. (1965) Electroslag remelting. Kiev: Naukova Dumka.

4. Medovar, B.I., Shevtsov, V.L., Marinsky, G.S. et al. (1978) Thermal processes in electroslag remelting. Kiev: Naukova Dumka.

5. (1974) Technology of fusion electric welding of metals and alloys. Ed. by B.E. Paton. Moscow: Mashinostroenie.

6. Nosatov, V.A. (1982) Investigation and development of electroslag casting technology of bimetal die billets: Syn. of Thesis for Cand. of Techn. Sci. Degree. Kiev: PWI

7. Ksyondzyk, G.V. (1973) Some principles of base metal penetration in circumferential electroslag surfacing. In: Proc. of All-Union Meeting on High-Efficiency Processes of Surfacing and Consumables (Kommunarsk, Sept. 1973), 26-33. Kiev: PWI.

8. Tarasevich, N.I. (1997) Formation of ingots and castings at controlled thermophysical action: Syn. of Thesis for Dr. of Techn. Sci. Degree. Kiev: FTIMS.

9. Demchenko, V.F. (1992) Calculation experiment in thermophysics of technological processes of welding and special electrometallurgy: Syn. of Thesis for Dr. of Techn. Sci. Degree. Kiev: PWI.

10. Baskakov, A.P. (1968) Rapid nonoxidation heating and heat treatment in boiling bed. Moscow: Metallurgiya.

11. Mikheev, M.A., Mikheeva, I.M. (1977) Principles of heat transfer. Moscow: Energiya.

Received 20.04.2015 